\section{How Do Specialist Teachers Practice Safety Lessons? Exploring the Aspects of Physical Education Safety Lessons in Elementary Schools}

\author{
Yongnam Park
}

\begin{tabular}{ll}
\hline Received: & 06 January 2018 \\
Revised: & 05 March 2018 \\
Accepted: & 13 March 2018 \\
ISSN: 1307-9298 \\
Copyright @ IEJEE \\
www.iejee.com
\end{tabular}

DOI: 10.26822/iejee.2018438136

\begin{abstract}
The purpose of this study was to investigate elementary PE specialist teachers' assessments of safety risk factors in PE class, risk management and difficulties in risk management. Five elementary PE specialist teachers who had at least five years of teaching experience participated in this study. Data were collected from non-participant class observations, in-depth interviews, and documents. Data were analyzed through the inductive categorical analysis. The results of this study are as follows: First, PE specialist teachers perceived that safe PE classes can be achieved by dealing with risks embedded within PE classes such as subject-innate, facility, environmental, and managerial components. Second, PE specialist teachers implemented safety classes by: (a) intentional class activities with detailed lesson plans, (b) reconstructing curriculum, and (c) making safety as a habit not as information acquisition. Third, participants had difficulty in teaching safety in PE classes due to: (a) outcome-oriented safety-first policy, (b) breach of safety codes between teacher and administrator, (c) limited contact with students, and (d) different level of sensitivity to safety issues. The findings suggest that teaching safety in PE classes are complex pedagogical activities that goes beyond teaching CPR or first aids and teacher education program should conceptualize safety issues from a pedagogical perspective.
\end{abstract}

Keywords: Physical education, specialist teacher, safety, safety classes

\section{Introduction}

Physical education (PE) teachers teaching physical activities and sports traditionally face the double-edged sword of "safety." Safety risk factors are embedded in all physical activities and sports. The goal of the PE curriculum is to educate students on the values of physical activities and sports while minimizing the risk of safety accidents (Bailey, 2002; Capel, 2000). A statement like the following can be found in PE curricula or teacher's guides in almost all countries: "PE teachers should encourage students to learn to take challenges and adventure and to compete through physical activities and sports." In fact, this statement is highly contradictory because safety and the values inherent in sports such as challenges, competition, and adventure are concepts completely opposed to each other.

In this regard, the PE curriculum in Korea, also called "the curriculum of the value of physical activities," is unique. It is an educational curriculum based on a new paradigm whereby in PE class students learn, not high jump and soccer, but the value of challenges through high jump and the value of competition through soccer. Interestingly, the PE curriculum presents "safety" as a core value for students to learn in addition to "health," "challenge," "competition," and "expression" (MEST, 2012). While safety is a critical educational issue in any country, the Korean PE curriculum emphasizes its importance more directly. While it is not explicitly stated in the curriculum, teaching safely as well as safety is a responsibility of PE teachers (Chappell, 2015; Robert, Danuta, \& Danuta, 2015).

In addition, elementary school students are more likely to be exposed to the risk of safety accidents than adults or middle and high school students (Caine, Maffulli, \& Caine, 2007). Because of the nature of the developmental process of elementary school students, they have great curiosity about their surroundings and their urge to explore their environment is strong. Due to these tendencies, their low level of judg- ment, self-regulation, and situational awareness place them at a higher risk of safety accidents than adults or adolescents (Micheli, Glassman, \& Klein, 2000).

There has been much research conducted investigating the injuries that can occur in PE class or analyzing safety risk factors (Kelly, 1997; Lariosa et al., 2017; Severs, 2003). However, little research has been conducted to explore the perception and practice of safe PE classes from the perspective of PE teachers who teach students. There has also been insufficient research conducted on safety risk factors in PE classes for elementary school students, who are still undergoing physical development. Accordingly, the present study aimed to investigate elementary school PE teachers' assessments of safety risk factors in PE class, risk management, and difficulties in risk management. The following specific research questions were addressed in the study:

1. What safety risks in PE classes do specialist teachers as sess?

2. How do specialist teachers teach safely and safety in PE classes?

3. What are the difficulties in teaching safely and safety in PE classes?

\section{Material \& Methods}

\section{Participants}

First, an initial pool of participants was chosen of ten PE specialist teachers who were attending graduate schools and the PE specialist teachers they recommended. Then, in following the purposeful sampling method (Creswell, 2009), teachers from the initial pool who met certain criteria were chosen as study participants: full-time elementary school teacher, specialist PE teacher with five years of experience or more, and currently teaching PE class as a specialist PE teacher. Five teachers were chosen, and their specific backgrounds are given in Table 1. Five study participants belonged to a 
Table 1. Background information on participants

\begin{tabular}{|c|c|c|c|c|c|c|c|}
\hline Pseudonym & Age / Gender & $\begin{array}{l}\text { Teaching } \\
\text { career }\end{array}$ & $\begin{array}{l}\text { Experience as } \\
\text { PE specialist }\end{array}$ & Region & Total students & $\begin{array}{c}\text { Number of } \\
\text { students per } \\
\text { class }\end{array}$ & Grade level \\
\hline Chansik & 37 / M & 11 years & 8 years & City & 143 & About 20 & $6^{\text {th }}$ \\
\hline Jina & $38 / F$ & 12 years & 5 years & City & 134 & About 20 & $6^{\text {th }}$ \\
\hline Nari & $30 / F$ & 8 years & 5 years & City & 125 & About 20 & $5-6^{\text {th }}$ \\
\hline
\end{tabular}

to a rural elementary school of a small city in Gyeongnam province located in the south of Korea, where summer temperatures are typically high and rainfall is abundant. All participants were asked to make efforts as teachers to enhance safety in PE class according to the Korean government's currently reinforced safety measures in school education.

\section{Data collection and analysis}

Data were collected through individual interviews, non-participant observation, and document review. Indepth interviews were conducted with individual participants using a semi-structured questionnaire for a tota of two sessions of 40 minutes each. The semi-structured questionnaire consisted of items regarding participants risk management strategies and positive experiences they had had while utilizing the strategies. Non-participant observation was conducted two to three times for each participant. Observations and field notes were made on the safety-related speeches and behaviors of each participant and their interactions with students before and during a PE class; additionally, pictures and videos were taken of the participant and students with their consent, which were analyzed later. Lastly, data useful for understanding the participants' strategies to manage safety-related issues during PE class were collected from the field documents (including the PE class lesson plans, PE safety manual, and teacher's guide developed by the Office of Education).

Inductive categorical analysis was performed on the collected data (Patton, 2002). First, significant content was underlined and analytic memos were compiled, while interviews were transcribed and field documents were transformed to research text. Initial coding was then performed on the transcribed data and research text for each participant in order to derive meaningful topics relevant to the issues of the present study. Subsequently, focused coding was performed to generate higher-level categories by grouping lower-level ones derived during early coding. To increase the trustworthiness of the research, early results of the analysis were shared with the study participants and member checks were performed to ensure that the data were not distorted. Additionally, to check for any errors in the research process, the entire research process was peer-debriefed with a university professor in sports pedagogy and three in-service teachers (Creswell, 2009).

\section{Results}

The results of this study are presented according to the three research questions on specialist teachers' risk assessments, strategies, and difficulties in risk management in PE classes

\section{Specialist teachers' risk assessment in PE classes}

PE specialists thought that skillful management of risk factors embedded in PE is the right way to lead safe PE classes, and that it is also part of teacher expertise. Factors threatening safety in PE class revealed in participants' narratives were generally classified into subject-innate components (e.g., sport performance risks), facility components (e.g., crowded gyms and old facilities), environmental components (e.g., inclement weather), and managerial components (e.g., lack of time and cursory safety inspection).

Safety risk factors in PE class perceived by participants were largely similar to what had been reported in earlier publications on risk factors for PE class safety (Chappell, 2015; Whitlam, 2003). The most interesting finding regarded participants' perceptions of environmental components. The examination of interviews and field documents showed that in addition to conventional factors threatening environmental safety such as temperature, rain, and snow (Chan \& Ryan, 2009; Edwards, et al., 2015; Goodman, Paskins, \& Mackett, 2012), participants focused on environmentally contaminants like fine dust and yellow sand storms. Since yellow sand storms blowing to Korea from the deserts in China contain various heavy metals such as magnesium and aluminum, the participants avoided PE classes for students' health during severe yellow dust storms. Moreover, In the PE safety manual used by participants, it is recommended not to hold an outdoor PE class if the air quality forecast is a "bad level of fine dust" (a forecast level of 121-200 $\mu \mathrm{g} / \mathrm{m}^{3}$ ) or "very bad level" (a forecast level of $201 \mu \mathrm{g} / \mathrm{m}^{3}$ or higher). When asked about how to handle weather with high levels of fine dust or yellow dust storms, one of the participants, Myeongho, said:

"if it is about other risk factors, I can conduct a PE class either by preventing them or paying attention to them. But on days when there is fine dust or a yellow dust storm is severe, I cannot hold a PE class in the outdoor field at all. It's not too hard to imagine why the term 'classroom PE' was created."

\section{Specialist teachers' risk management in PE classes}

All teachers have rights and responsibilities for the class they teach. Safety legislation and regulations in every country specify the responsibilities of a teacher as those of a supervisor, and thus it is widely accepted that maintaining safety in the classroom is a "duty" of a teacher (Raymond, 1999; Whitlam, 2005). Based on the analysis of the data collected in the present study, PE specialists' risk management strategies were categorized into the following types: (a) intentional class activities with detailed lesson plans, (b) reconstructing the curriculum, and (c) making safety a habit, not a process of information acquisition.

\section{Intentional class activities with detailed lesson plans}

"To prevent safety accidents, everything must be planned before the class: Whether or not there are any risk factors in the facility and the equipment, which of the activities during the class have a risk of accidents, whether there are any students in poor physical condition today. The teacher should be 
aware of all these things and prepare for alternatives before beginning the class. So far, there has never been a serious safety accident in my PE class."

As shown in the interview with Jina, participants thought that it is important for a teacher to be preemptively aware of the expected safety accident types for a given physical activity. A review of participants' lesson plans revealed that they identify students' physical features, examine the facility and the equipment, and prepare warm-up and cool-down exercises to prevent exercise injury at a highly detailed level.

\section{Reconstructing the curriculum}

Participants did not blindly trust the physical activities introduced in the textbooks. They exercised skepticism regarding safety and, if a certain exercise had risks that were excessive or difficult to prevent, either modified it or replaced it with a safer alternative. In relation to this, Nari reported the following:

"When I first started out as a teacher, I used the physical activities introduced in the textbook as-is. As I accumulated experience in school after school, however, I understood that the same physical activity could have different risk levels depending on the PE class environment. Since then, I show students the activities I reconstruct to teach safely in my class environment."

A teacher should teach an education curriculum, not a textbook (Jewett, Bain, \& Ennis, 1995). From this perspective, participants deserve to receive support for their proactive attempts to reconstruct the curriculum to teach PE classes safely. However, they had the idea of reconstructing the curriculum to ensure safe PE classes based only on their own experience. In this respect, Chansik stated the following:

"It seems that I acquired the idea of reconstructing the curric ulum little by little, as I failed to conduct safe PE classes. After some students were injured or put in a dangerous situation, I figured it out by myself. I have participated in PE teacher training programs for PE class safety, but every one of them taught only CPR or emergency protocols. Such programs are not really helpful to teachers in increasing their expertise in the reconstruction of the curriculum."

\section{Making safety as a habit not as information acquisition}

According to the PE class observation, at the beginning of a PE class the participants provided detailed explanations of safety accidents that could occur during the class to make students aware of safety risk factors before participating in activities. However, participants believed that rather than such a cognition-focused strategy, it is more effective for students to form the habit of maintaining a sensitive attitude toward safety, not only in PE class but in school life overall. Indeed, such mottos as "safety is a habit for students to have" and "my safety is others' safety" were posted in the corridors of the school building where Kyeongho and Nari worked. That is, the habituation strategy is to the general context of students' everyday lives as the cognitive strategy is to the specific content of PE curriculum. To the question why the viewpoint of safety as a habit is important, Kyeongho responded as follows:

"Especially in elementary school, safety is closely tied to every day lifestyle habits. Teaching safety should be done in the context of everyday activities. Emphasizing safety just in the subject classes has no effect."

Specialist teachers' difficulties in risk management in PE class

The analysis of the difficulties in PE class risk management experienced by the participants showed that the following three contradictory perceptions of PE class safety were present in the school community: (a) an outcome-oriented safety-first policy (process vs. outcome), (b) breaches of safety codes between teachers and administrators (prevention vs. responsibility), (c) limited contact with students (classroom teachers vs. specialist teachers), and (d) different levels of sensitivity to safety issues (sensitive teachers vs. insensitive students).

Outcome-oriented safety-first policy: process vs. outcome The PE class safety manual the participants used specifies that safety accidents occurring in PE class must be reported to the School Safety and Insurance Federation, which are then reflected in the assessment of the school. In other words, a school with a high proportion of safety accidents in PE class is highly likely to receive a lower score in school assessments and may be put at a disadvantage in securing the next year's budget. Consequently, participants were implicitly forced by the principals to make safety a top priority when conducting PE class. In an extreme case, the schools where some participants were working had cultivated the atmosphere of not reporting a safety accident if the injury was not serious. In such a situation, participants were reluctant to teach physical activities or sports with the risk of safety accidents. Jina expressed her concern over the outcome-oriented safety-first policy as follows:

"Once an accident occurs in a PE class, the teacher's efforts for safe PE classes are just useless. If the policy stressing safety over education continues, teachers cannot help but decide not to teach an activity with even a slight risk."

Breaches of safety codes between teacher and administrator: prevention vs. responsibility

The most serious difficulty experienced by participants when trying to conduct safe PE classes was the reality that they (specialist PE teachers) and the school administrator have completely different orientations with respect to safety. Participants pointed out that specialist PE teachers are committed to the "prevention of safety accidents" in PE class, whereas the school administrator is interested in "safety accident liability." Also, they emphasized that the prevention of and liability for safety accidents fall on everyone, but that the school organization is bureaucratic, where each member fulfills his or her role and takes responsibility for that role. On this point, Nari said the following:

"Administrators are only interested in whose PE class the accident occurred in and whose fault it was, and just want to receive a process report on the safety accident. There are times when my efforts for students not to be injured are regarded as unimportant and they wouldn't even listen to me."

Limited contact with students: Classroom teachers vs. specialist teachers

Subject specialist teachers in each country have long and complicated histories, but their profession has emerged to enhance the teacher professionalism frequently mentioned in elementary education (Barney \& Deutsch, 2012; Brooks \& Thompson, 2015). Although specialist teachers were introduced to provide quality subject classes to students, the research participants reported that specialist teachers play a minor role in the safety of students' PE classes.

Chansik: "Jione, why are you standing there doing nothing? What's going on?"

Jione: ....... (silence) 
Unknown: "She had an argument with a classmate in the classroom this morning. She's in a bad mood, after that. "

(field notes, Chansik's PE class)

At the beginning of each lesson I ask students about their physical condition and pick out the students who cannot always attend classes. Since I am not a classroom teacher unless students tell me, I have no idea what trouble a student is having and how and how much he/she is sick. Also, it is difficult for a specialist teacher to comprehend the tendencies, behavior, and habits of all students. (Myeongho, interview)

The research participants point out the limits they face by not learning in detail about the situations, health, and psychological conditions of their students because they are not classroom teachers. In elementary education, it is very important for the teacher to observe and communicate with the student in close contact. For a safe PE class, the teacher's deep understanding of each student should be assumed. Specialist teachers have an advantage in forming subject matter knowledge or curricular knowledge, as proposed by Shulman (1987), in that they focus on one specific subject and prepare and run that class. Participants had expertise in "teaching PE well" with abundant subject knowledge and teaching techniques in practice. However, they showed weaknesses in their knowledge of learners and their characteristics, which is necessary for teaching activities, because they have less opportunity to come into contact with their students than classroom teachers. Lack of understanding of their students was a major factor in lowering confidence in the participants' expertise in "teaching PE safely."

Different levels of sensitivity to safety issues: sensitive teachers vs. insensitive students

Once again, from the field notes:

Jina: "Soo-Mi, bend more. If you don't stretch your back properly, you may hurt it later when you throw the ball."

Soo-mi: [As if annoyed] "I have never been injured in a PE class."

Myeongho: "Always make sure that there is no one in front of you before you throw a flying disk."

Unknown: "Don't worry, teacher. Even if I get hit by one, it never hurts me."

A gap in PE class safety also existed between students and teachers. As shown in the field notes made during non-participant oservation of the PE classes, students seemed oblivious to PE class safety, unlike teachers, who were sensitive to safety issues. Participants were sometimes observed to be upset or to caution students in a stern manner when they did not observe safety rules or talked as if those rules were nothing serious. Kyeongho said,

"even if I try to teach safe physical activities and sports, it is the students who own the moving bodies. Thus, those who should make the most efforts for safe PE classes are none other than students."

\section{Discussion}

The present study was conducted with specialist PE teachers in elementary schools to explore their perceptions and practices of PE class safety. Specifically, their PE class risk assessments, risk management strategies, and difficulties in risk management were examined.
First, it was found that PE class risk assessment and the ability to perform risk management are an important expertise that teachers possess. Risk factors for PE class safety accidents differ vastly according to context, and thus a teacher should assess risk in a thoughtful manner and manage it according to the context (Chappell, 2015). If a teacher lacks such expertise, the dream of becoming a PE teacher may end up being a dream of "Killer Jobs." (Finn et al., 2017)

Second, the present study findings are a reminder that attention should be paid to thoughtless education hidden behind the widespread safety-first policy. As confirmed in the study, school management emphasizing outcome-oriented safety-first policies and prioritizing liability over prevention, despite teachers' efforts to practice teaching safely and safety in PE class, induces teachers to think that "if there is a risk, we don't teach." Many PE teachers decide whether or not to teach a certain physical activity by determining whether the benefits of the activity outweigh the risk or the risk outweighs the benefits (Beaumont, 2007, p. 31 ), and holding too tightly to a safety-first policy reduces teachers' desire for education and shrinks educational activities, the harms of which are passed onto the students. Thoughtless education is more dangerous than obliviousness to safety.

Third, the results suggest that safety assessments in PE classes are focused on prevention and quantitative methods. Of course, prevention is a keyword that should be given priority over anything else in safety. A series of tasks for teachers to assess and manage PE class risks serves to prevent safety accidents in PE classes. However, attention should not be focused on "how many safety accidents were prevented in PE classes?" The assessment items should include the school staff's efforts to prevent accidents and what actions they have taken in the event of an accident. In order to do so, it is necessary to implement methods of qualitative analysis of the safety manual and safety incident cases of the unit school while avoiding a quantitative evaluation that merely counts the incidents of safety accidents or the number of safety education activities.

\section{Conclusions}

The present study findings can contribute to increasing the understanding of specialist PE teachers' risk assessment, risk management, and difficulties in risk management in elementary school PE class. The results suggest that teaching safely and safety in PE classes involves complex pedagogical activities. Teachers should have an accurate understanding of sports facilities and equipment needed for class and the sport that is the content of PE class while perceiving students' physical condition and risk factors in terms of their teaching methods. Based on such risk assessment of PE class, teachers should be able to establish strategies to perform risk management. Teacher education programs should conceptualize safety issues from a pedagogical perspective so that safety classes can be a stepping stone rather than a stumbling block to other PE activities. Especially, expertise in assessing and managing the safety risk in PE class should be addressed seriously in both pre- and in-service teacher education programs. In addition, the lack of teachers' perceptions of the emotional and psychological aspects of safety shows that teachers conceptualized safety as a mere physical issue rather than a holistic issue encompassing both physical and psychological aspects. 


\section{References}

Bailey, R. (2002). Questioning as a teaching strategy in physical education. The Bulletin of Physical Education, 38(2), 119-126.

Barney, D. \& Deutsch, J. (2012). Attitudes and perceptions of elementary classroom teachers use of physical education time for planning. International Electronic Journal of Elementary Education, 4(2), 367-376. Retrieved December 1, 2017, from https://www. iejee.com/index.php/IEJEE/article/view/204

Beaumont, G. (2007). Health and Safety. Physical Education Matters, 2(1), 31.

Brooks, C. \& Thompson, M. D. (2015). Insideness and outsideness: An autoethnography of a primary physical education specialist teacher. European Physical Education Review, 21(3), 325-339. doi: $10.1177 / 1356336 \times 14568126$

Caine, D., Maffulli, N., \& Caine, C. (2007). c: Injury rate, risk factors, and prevention. Clinics in Sports Medicine, 27(1), 19-50. doi: 10.1016/j.csm.2007.10.008

Capel, S. (2000). Re-reflecting on priorities for physical education: now and in the twenty- first century. In S. Capel, and S. Piotrowski (Eds.), Issues in Physical Education (pp. 209-220), London: Routledge.

Chan, C. \& Ryan, D. (2009). Assessing the effects of weather conditions on physical activity participation using objective measures. International Journal of Environmental Research and Public Health, 6, 26392654. doi: 10.3390/ijerph6102639

Chappell, A. (2015). Teaching safely and safety in PE. In S. Capel and M. Whitehead (Eds.), Learning to teach physical education in the secondary school (4th ed., pp. 184-203), London: Routledge.

Creswell, J. W. (2009). Research design: Qualitative, quantitative, and mixed methods approaches (3rd ed.). Thousand Oaks, CA: Sage.

Edwards, N., Myer, G. Kalkwarf, H., Woo, J., Khoury, P., Hewett, T., \& Daniels, S. (2015). Outdoor temperature, precipitation, and wind speed affect physical activity levels in children: A longitudinal cohort study. Journal of Physical Activity and Health, 12, 1074 -1081. doi: 10.1123/jpah.2014-0125

Finn, D., Ammon, R., Mahoney, K., Fried, G., \& Arkoubi, K. (2017). Killer jobs: The dark side of being a physical education teacher. Strategies, 28(3), 34-39. doi: 10.1080/08924562.2015.1025166

Goodman, A., Paskins, J., \& Mackett, R. (2012). Day length and weather effects on children's physical activity and participation in play, sports, and active travel. Journal of Physical Activity and Health, 9, 1105-1116. PMCID:PMC3584676

Jewett, A. E., Bain, L. L., \& Ennis, C. D. (1995). The curriculum process in physical education (2nd ed.). Dubuque: Brown \& Benchmark.

Kelly, L. (1997). Safety in PE. In S. Capel (ed.), Learning to teach physical education in the secondary school: $A$ companion to school experience (pp. 115-219), London: Routledge.
Lariosa, C., Gozdowsk, D., Pietkiewicz, S., \& Maciejewski, R.(2017). Survey of judo injuries in physical education classes: a retrospective analysis. Journal of Physical Education and Sport, 17(3), 2034-2042. doi:10.7752/jpes.2017.03205

Micheli, L. J., Glassman, R., \& Klein, M. (2000). The prevention of sports injuries in children. Clinics in Sports Medicine, 19(4), 821-834. doi: 10.1016/S02785919(05)70239-8

Ministry of Education, Science and Technology (MEST) (2012). Physical Education Curriculum of the Republic of Korea. Seoul: MEST.

Patton, M. (2002). Qualitative research and evaluation methods (3rd ed.). Thousand Oaks, CA: Sage Publications.

Raymond, C. (1999). Safety across the curriculum. London: Falmer Press.

Robert, P, Danuta, Z., \& Danuta, N. (2015). Problems of safety and risk in physical education. Pedagogics, Psychology, Medical-biological Problems of Physical Training and Sports, 10, 82-89. doi: 10.15561/18189172.2015.1013

Severs, J. (2003). Safety and risk in primary school physical education: A guide for teacher. London: Routledge.

Shulman, L. (1987). Knowledge and teaching: Foundations of the new reform. Harvard Educational Review, 57(1), 1-23. doi: 10.17763/haer.57.1. j463w79r56455411

Whitlam, P. (2003). Risk management principles. In J. Severs (Ed.), Safety and risk in primary school physical education (pp. 30-42), London: Routledge.

Whitlam, P. (2005). Case law in physical education and school sport: A guide to good practice. Leeds: BAALPE/ Coachwise. 